\title{
Prevalencia de vaginosis bacteriana, Actinomyces spp., Candida spp. y Trichomonas vaginalis en usuarias del dispositivo intrauterino (DIU), Medellín, Colombia, 20 I I-2013
}

Prevalence of bacterial vaginosis, Actinomyces spp., Candida spp., and Trichomonas vaginalis in intrauterine device (IUD) users, Medellin, Colombia, 201 I-2013

J. Lorena Ramos-Burgos MB', Luisa F. Campuzano-López MB', Marleny Valencia-Arredondo PhD², Jaiberth A. Cardona-Arias $\mathrm{MSc}^{3}$

Introducción: el uso del dispositivo intrauterino incrementa el riesgo de algunas infecciones genitales. Objetivo: determinar la prevalencia de vaginosis bacteriana, Actinomyces spp., Candida spp. y Trichomonas vaginalis en usuarias del dispositivo intrauterino. Materiales y métodos: se realizó un estudio transversal en usuarias del dispositivo intrauterino, atendidas en un programa de tamización de cáncer cérvico-uterino en Medellín, Colombia, entre 201 I y 2013 . Se empleó una fuente de información secundaria basada en los registros citológicos del laboratorio clínico, se calculó la prevalencia global de las cuatro infecciones y las prevalencias específicas según grupo etario y sector de residencia, con un intervalo de confianza del 95\%. La exploración de asociaciones se hizo con la prueba chi cuadrado de Pearson. Resultados: Se registraron 12.541 usuarias del dispositivo intrauterino de 10 comunas de Medellín. La edad promedio fue 34,0 99,8 años; el 50\% de los valores centrales estuvo entre 26 y 4 I años. Las prevalencias de infecciones vaginales fueron: vaginosis bacteriana 25,6\%, Actinomyces spp. 8,9\%, Candida spp. 5, I\% y Trichomonas vaginalis 1,2\%. La prevalencia de vaginosis bacteriana y Candida spp. fue estadísticamente mayor en adolescentes y jóvenes. La prevalencia de las cuatro infecciones fue estadísticamente diferente según el sector de residencia. Conclusión: en usuarias del dispositivo intrauterino las principales infecciones genitales son vaginosis bacteriana y Actinomyces spp., las adolescentes y jóvenes son los grupos de mayor riesgo para vaginosis bacteriana y Candida spp. y la ocurrencia de infecciones varía entre los sectores de la ciudad; información relevante para la planeación de programas de prevención y atención.

\footnotetext{
' Estudiante Microbiología y Bioanálisis. Grupo de investigación Salud y Sostenibilidad, Universidad de Antioquia. Medellín, Colombia. ${ }^{2}$ Bacterióloga y Laboratorista Clínica, Especialista en Citología Ginecológica, MSc y PhD en Salud Pública. Docente Escuela de Microbiología, Universidad de Antioquia. Medellín, Colombia.

${ }^{3}$ Microbiólogo y Bioanalista. MSc en Epidemiología. Docente Escuela de Microbiología, Universidad de Antioquia y Facultad de Medicina, Universidad Cooperativa de Colombia. Medellín, Colombia. Correspondencia: Calle 67 \#53-108, Bloque 5, oficina 103. Teléfono: 5742198486 . Fax: 574 2195486. Correo electrónico: jaiberthcardona@gmail.com
}

Conflicto de intereses: los autores declaran que no tienen conflicto de intereses Medicina \& Laboratorio 2015; 21: 455-464

Módulo 19 (Investigación), número 39. Editora Médica Colombiana S.A. $2015^{\circ}$

Recibido el 30 de septiembre de 2015; aceptado el 31 de octubre de 2015 
Palabras clave: prevalencia, dispositivos intrauterinos, vaginosis bacteriana, Actinomyces, Candida, Trichomonas vaginalis.

Introduction: The use of intrauterine device increases the risk of genital infections. Objective: To determine the prevalence of bacterial vaginosis, Actinomyces spp., Candida spp., and Trichomonas vaginalis in intrauterine device users. Material and methods: A cross-sectional study was performed in intrauterine device users attended in a screening program for cervical cancer in Medellín, Colombia, between 2011 and 2013. A source of information was secondary, based on the records of the clinical laboratory of cytology. The overall prevalence of the four infections and specific prevalence by age group and residence area was calculated, all with confidence intervals of 95\%. To explore associations Pearson chi-square test was used. Results: It was registered 12,54 I users of the intrauterine device from 10 districts of Medellin. The users mean age was $34.0 \pm 9.8$ years; $50 \%$ of the central values was between 26 and 4 I years. The prevalence of vaginal infections were: bacterial vaginosis 25.6\%, Actinomyces spp. 8.9\%, Candida spp. 5.1\% and Trichomonas vaginalis 1.2\%. The prevalence of bacterial vaginosis and Candida spp. was statistically higher in adolescents and youth. The prevalence of the four infections was statistically different according to the residence sector.

Conclusion: in intrauterine devices users the major genital infections are bacterial vaginosis and Actinomyces spp. Adolescents and young people are the groups most at risk for bacterial vaginosis and Candida spp. and the occurrence of infections varies between sectors of the city; information that is relevant for planning prevention and care programs.

Keywords: Prevalence, intrauterine devices, bacterial vaginosis, Actinomyces, Candida, Trichomonas vaginalis.

Ramos-Burgos JL, Campuzano-López LF, Valencia-Arredondo M, Cardona-Arias JA. Prevalencia de vaginosis bacteriana, Actinomyces spp., Candida spp. y Trichomonas vaginalis en usuarias del dispositivo intrauterino (DIU), Medellín, Colombia, 20II-2013. Medicina \& Laboratorio 20I 5; 21: 455-464.

L as infecciones del tracto genital inferior se diferencian en tres tipos: de transmisión sexual, endógenas (candidiasis o vaginosis bacteriana) e iatrogénicas [I]. Dentro de estas, las infecciones de transmisión sexual continúan teniendo un profundo impacto en la salud sexual y reproductiva pues hacen parte de las cinco primeras causas de atención médica en el mundo y, de acuerdo a los datos publicados en 2013 por la Organización Mundial de la Salud (OMS), se estima que en un año aproximadamente quinientos millones de personas adquieren una infección de transmisión sexual sin incluir la infección por el virus de la inmunodeficiencia humana $(\mathrm{VIH})$. La mayor proporción de este tipo de infecciones se observa en Asia meridional y sudoriental, seguida por el África subsahariana y América Latina y el Caribe [2,3]. En Colombia, según lo reportado por el Instituto Nacional de Salud, en el período de 2009 a 20 I I, se reportaron alrededor de 94.000 personas que consultaron por una infección de transmisión sexual [4].

Particularmente, las infecciones vaginales presentan una etiología diversa con diferentes microorganismos implicados como Trichomonas vaginalis, Candida spp., Gardnerella vaginalis, Chlamydia trachomatis, entre otros [5,6]. Igualmente, es importante denotar que el 75\% de todas las mujeres en el mundo presentaran en su vida al menos un episodio de candidiasis [7]. La tricomoniasis es considerada la infección de transmisión sexual curable más común. En Colombia, en 201 I, se presentaron 1.995 nuevos casos de esta infección [4,8]. Por su parte, la vaginosis 
bacteriana es la infección más común en mujeres de los 15 a los 44 años de edad, con una prevalencia que varía entre el 10\% y el $40 \%$ [9-I I].

De otro lado, la guía de práctica clínica para la prevención, diagnóstico y tratamiento de la actinomicosis reportó 1.774 mujeres con un diagnóstico de actinomicosis, de las cuales el 38\% eran usuarias del dispositivo intrauterino (DIU) [12]. Este tipo de infecciones se caracterizan por un flujo vaginal con síntomas como molestia o ardor en la región vaginal, dolor pélvico, prurito y mal olor genital $[5,6]$. Esta infección afecta a mujeres de cualquier edad y los factores asociados incluyen el inicio temprano de la actividad sexual, el número de parejas sexuales, las relaciones sexuales sin protección, la propagación anormal del microorganismos o cambios en la microbiota como resultado de tratamientos con antibióticos, el uso de anticonceptivos orales, la diabetes, cualquier estado de inmunosupresión y el uso del dispositivo intrauterino, entre otros [13].

Según la Encuesta Nacional Colombiana de Demografía y Salud, en 20 10, 93\% de las mujeres conocía el dispositivo intrauterino y el 5,6\% lo utilizaba como método anticonceptivo [14]. Este dispositivo puede ser de dos tipos: a) inertes, elaborados en un material no absorbible como polietileno impregnado con sulfato de bario para darles radio-capacidad y b) aquellos en los que se genera la eliminación de una sustancia químicamente activa (cobre o un agente progestágeno). Para facilitar su localización y retirada la mayoría de los dispositivos intrauterinos llevan una cola o filamento de plástico recubierto con nailon. No obstante, el tipo de relación entre las infecciones y el uso del dispositivo intrauterino aún no es clara, ya que no existen datos precisos que evidencien el papel de este dispositivo en la infección [15,16].

Para el diagnóstico de las infecciones, en primera instancia, se utiliza el análisis en fresco y la coloración de Gram, aunque también se dispone de otras herramientas como el cultivo y la serología. A su vez, la citología convencional con terminología Bethesda, mediante la coloración de Papanicolaou, es una prueba sensible y específica que permite una buena observación de los microorganismos causantes de infecciones vaginales clasificándolos así: Trichomonas vaginalis, hongos compatibles con Candida spp., cambios de la microbiota vaginal normal sugestiva de vaginosis bacteriana y bacterias de características morfológicas compatibles con Actinomyces spp. La citología tiene otra ventaja para este tipo de diagnósticos que radica en que es una prueba de tamización de gran cobertura y a la cual tienen acceso la gran mayoría de las mujeres, logrando hacer diagnóstico incluso en mujeres asintomáticas [5, 17-20].

Las investigaciones disponibles en la literatura sobre las infecciones vaginales se han desarrollado principalmente en la población general y, por tanto, no han sido aplicadas en poblaciones con posibles riesgos específicos como las usuarias del dispositivo intrauterino. Particularmente, en Medellín no se dispone de evidencias sobre la magnitud de este grupo de infecciones en mujeres con el dispositivo. Si bien los estudios sobre la ocurrencia de una infección no permiten establecer asociaciones causales, este tipo de investigaciones constituyen el primer paso para determinar si la ocurrencia del evento varía en la población de usuarias del dispositivo intrauterino como base para el diseño de investigaciones analíticas y la exploración del riesgo específico de esta población. Teniendo en cuenta lo anterior, el objetivo de este estudio fue determinar la prevalencia de vaginosis bacteriana, Actinomyces spp., Candida spp. y Trichomonas vaginalis en usuarias del dispositivo intrauterino atendidas en un programa de tamización de cáncer cervicouterino, en Medellín, Colombia, entre 2011 y 2013. 


\section{Materiales y métodos}

\section{Tipo y población de estudio}

Se realizó un estudio descriptivo transversal en usuarias del dispositivo intrauterino, atendidas durante tres años (20 I I a 2013) en un programa de tamización de lesiones preneoplásicas de cáncer cervicouterino con cobertura en todas las comunas de Medellín, Colombia.

\section{Recolección de la información}

La información se tomó de las bases de datos de 50 unidades hospitalarias del programa de tamización mencionado. En estas bases de datos se registra información básica de cada mujer como la edad (categorizada como adolescentes para aquellas entre 10 y 19 años, adultas jóvenes entre 20 y 44 años, adulto medio entre 44 y 64 años y adulto mayor a partir de los 65 años), EPS, método de planificación y resultados de la evaluación oncológica y microbiológica de la prueba de Papanicolaou, reportados de acuerdo al sistema Bethesda 2001.

\section{Control de sesgos}

La información consignada en la base de datos del laboratorio clínico cuenta con un sistema de información de calidad del dato, enmarcado en el programa de gestión de la calidad. Los posibles sesgos de información de la extracción de los datos se controlaron haciendo una valoración de la reproducibilidad intra e interobservador, tomando los datos de un mes y haciendo dos extracciones independientes, con un rango de un mes, por parte de dos revisores.

\section{Análisis de la información}

La descripción del grupo de estudio se realizó con frecuencias, se calculó la prevalencia global de cada infección y específica según grupo etario y sector de residencia, con sus respectivos intervalos de confianza del 95\%. La comparación de las prevalencias de infección según el grupo etario se hicieron con la prueba chi cuadrado de tendencia lineal, mientras que las comparaciones con el sector de residencia se realizaron a través de la prueba chi cuadrado de Pearson. Los análisis se hicieron con una significación estadística de 0,05 utilizando el programa SPSS (Statistical Package for the Social Sciences) Versión 21 .0 (SPSS Inc., an IBM Company, Chicago, Illinois, Estados Unidos).

\section{Aspectos éticos}

Se tomaron como referentes normativos la Declaración de Helsinki y la resolución 8430 de 1993 del Ministerio de Salud de Colombia; esta última clasifica el estudio como una investigación sin riesgo.

\section{Resultados}

\section{Características demográficas de las usuarias del dispositivo intrauterino}

Durante el período de estudio (20 I I-20 I 3) se registraron I 2.54 I usuarias del dispositivo intrauterino atendidas en el programa de tamización de cáncer cervicouterino. La edad promedio 


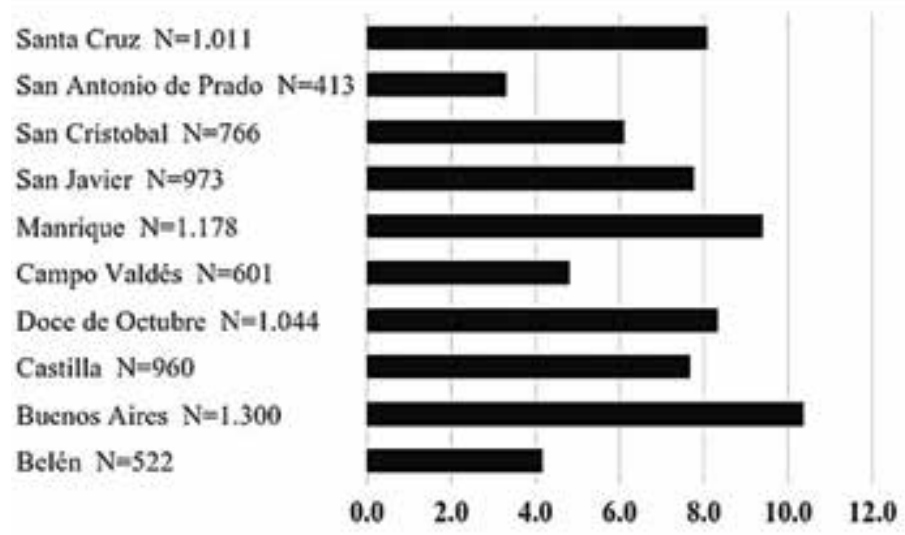

Figura I. Distribución porcentual del lugar de residencia de las mujeres del estudio.

de las usuarias fue de 34,0 \pm 9,8 años; el 50\% de los valores centrales estuvo entre 26 y 4 I años, con un rango de 14 a 82 años. La distribución por grupos etarios fue 3,7\% adolescentes, $79,1 \%$ adultas jóvenes, $16,9 \%$ adultas medias y $0,2 \%$ adultas mayores.

En relación con el sector de residencia de las usuarias del dispositivo en la ciudad de Medellín, el barrio Buenos Aires presentó la mayor proporción con 10,4\%, seguido del barrio Manrique con 9,4\%, el Doce de Octubre con 8,3\% y Santa Cruz con 8,1\%. Los barrios de menor frecuencia fueron San Antonio de Prado con 3,3\%, Belén con 4,2\% y Campo Valdés con 4,8\%. En el 30, I\% no se reportó un lugar de residencia fijo (véase figura I).

\section{Prevalencia de infecciones vaginales en las usuarias del dispositivo intrauterino}

La prevalencia de las infecciones vaginales incluidas en el estudio fue: vaginosis bacteriana 25,6\%, Actinomyces spp. 8,9\%, Candida spp. 5, I\% y Trichomonas vaginalis I,2\%. La prevalencia de la vaginosis bacteriana presentó asociación estadística con el grupo etario, siendo mayor en las adolescentes y jóvenes con un $29,8 \%$ y $26,4 \%$, respectivamente, y descendiendo hasta el 13,3\% en el grupo de adultas mayores. De forma similar, se halló una asociación en la prevalencia de Candida spp. y el grupo etario, con una mayor ocurrencia en las adolescentes y jóvenes, con $6,2 \%$ y 5,5\%, respectivamente. La prevalencia de Actinomyces spp., a pesar de no mostrar asociación estadística con el grupo etario, presentó una prevalencia más alta entre las mujeres mayores de 64 años (véase tabla I). Vale la pena resaltar que ninguna de las pacientes incluidas en este estudio presentaron en sus citologías cambios citopáticos asociados a la infección por el herpesvirus humano (tipo I o 2), los cuales se incluyen en el sistema Bethesda.

La prevalencia de las cuatro infecciones fue estadísticamente diferente según el sector de residencia. En el caso de la vaginosis bacteriana la mayor prevalencia específica se presentó en Buenos Aires y la menor en Doce de Octubre y Belén; de Actinomyces spp. las mayores prevalencias se presentaron en Manrique, San Cristóbal y Santa Cruz, y las menores en Doce de Octubre y Campo Valdés; en cuanto a Candida spp. fue mayor en Buenos Aires, Castilla y San Antonio de Prado, y menor en Manrique, finalmente para Trichomonas vaginalis fue mayor en San Antonio de Prado y menor en Castilla y Doce de Octubre (véase tabla I). 


\begin{tabular}{|c|c|c|c|c|}
\hline \multirow{2}{*}{ Prevalencia } & \multicolumn{4}{|c|}{ Proporción (IC 95\%) } \\
\hline & Vaginosis bacteriana & Actinomyces spp. & Candida spp. & Trichomonas vaginalis \\
\hline Global & $25,6(24,8-26,4)$ & $8,9(8,4-9,4)$ & $5,1(4,7-5,5)$ & $1,2(1,0-1,4)$ \\
\hline \multicolumn{5}{|c|}{ Específica por grupo etario } \\
\hline Adolescente & $29,8(25,5-34,0)$ & $8,1(5,5-10,7)$ & $6,2(3,9-8,4)$ & I, I $(0,4-2,5)$ \\
\hline Adulto joven & $26,4(25,5-27,2)$ & $9,0(8,4-9,5)$ & $5,5(5,0-5,9)$ & ।,2( $(1,0-1,4)$ \\
\hline Adulto medio & $21,4(19,6-23,2)$ & $8,7(7,4-9,9)$ & $3,2(2,4-4,0)$ & $0,9(0,5-1,4)$ \\
\hline Adulto mayor & I3,3 (3,7-30,7) & $16,7(5,6-34,7)$ & 0,0 & 0,0 \\
\hline Valor $\mathrm{p} \mathrm{Chi}^{2}$ tendencia & $0,000^{* *}$ & 0,799 & $0,000^{* *}$ & 0,345 \\
\hline \multicolumn{5}{|c|}{ Específica por sector de residencia } \\
\hline Belén & $22,8(19,1-26,5)$ & $7,5(5,1-9,8)$ & $5,7(3,6-7,8)$ & I,5 $(0,4-3,7)$ \\
\hline Buenos Aires & $28, I(25,6-30,6)$ & $9,4(7,8-11,0)$ & $6,8(5,4-8,3)$ & I,I $(0,5-1,7)$ \\
\hline Castilla & $25,8(23,0-28,6)$ & $7,3(5,6-9,0)$ & $6,8(5, \mid-8,4)$ & $0,8(0,2-1,5)$ \\
\hline Doce de Octubre & $22,8(20,2-25,4)$ & $6,1(4,6-7,6)$ & $5,3(3,9-6,7)$ & $0,5(0,2-1,1)$ \\
\hline Campo Valdés & $24,8(21,3-28,3)$ & $5,5(3,6-7,4)$ & $5,8(3,9-7,8)$ & $2,2(0,9-3,4)$ \\
\hline Manrique & $27,9(25,3-30,5)$ & I0,0 (8,3-। |,8) & $3,5(2,4-4,6)$ & I,0 $(0,4-1,6)$ \\
\hline San Javier & $25,4(22,6-28,2)$ & $9,2(7,4-11,1)$ & $4,5(3,2-5,9)$ & I,3 $(0,6-2,1)$ \\
\hline San Cristóbal & $23,6(20,6-26,7)$ & $10,4(8,2-12,7)$ & $4,3(2,8-5,8)$ & I,7 $(0,7-2,7)$ \\
\hline San Antonio de Prado & $26,4(22,0-30,8)$ & $6,8(4,2-9,3)$ & $6,5(4,0-9,0)$ & $2,7(10,-4,3)$ \\
\hline Santa Cruz & $26,5(23,7-29,3)$ & $10,5(8,5-12,4)$ & $4,6(3,3-6,0)$ & ।,2 (0,5-1,9) \\
\hline Valor p Chi ${ }^{2}$ & $0,041^{*}$ & $0,000^{* *}$ & $0,005^{* *}$ & $0,020^{*}$ \\
\hline $\begin{array}{l}\text { *Valor } p<0,05 \\
* \text { *Valor } p<0,01\end{array}$ & & & & \\
\hline
\end{tabular}

\section{Discusión}

La prevalencia general de resultados positivos en la citología de usuarias del dispositivo intrauterino incluidas en este estudio evidenció que la vaginosis bacteriana fue la más prevalente, seguida de Actinomyces spp., la candidiasis y, en menor proporción, la tricomoniasis. Esto difiere de estudios previos realizados en la población general en los que se ha reportado una alta prevalencia de vaginosis bacteriana y candidiasis [21,22], lo que pone de manifiesto el incremento de la prevalencia de Actinomyces spp. en las usuarias del dispositivo.

La vaginosis bacteriana presentó una prevalencia global elevada; lo que concuerda con otros estudios de Medellín (Colombia), y España en los que esta infección presenta elevada ocurrencia, siendo mayor en usuarias del dispositivo intrauterino frente a las mujeres que usan otros métodos de planificación [23,24]. Igualmente, un estudio en Chile reportó que las mujeres que utilizaban el dispositivo intrauterino presentan 3,6 veces más riesgo de contraer esta infección [25]. Las adolescentes y adultas jóvenes fueron los grupos etarios que presentaron mayor prevalencia de vaginosis bacteriana, de igual manera a lo reportado por Martínez y colaboradores (20।3) [26], en el que el 31,9\% de las adolescentes fueron positivas para esta infección. Así mismo, en el estudio de Tamayo y colaboradores (2010) [27] las adolescentes y las mujeres 
adultas jóvenes presentaron las frecuencias más altas de vaginosis bacteriana. En el caso de las adolescentes, esto puede deberse al aumento de factores de riesgo como el inicio temprano de relaciones sexuales, bajo uso o uso indebido de métodos de protección, además de condiciones sicosociales que hacen de las adolescentes una población vulnerable [28].

Si bien en la población general las infecciones vaginales más comunes son la vaginosis bacteriana, la candidiasis y la tricomoniasis, en este caso Actinomyces spp. presentó la segunda prevalencia más alta (8,9\%), lo que coincide con el estudio de Arenas y colaboradores (20 I5) [29] donde la prevalencia de esta infección fue mayor en las usuarias del dispositivo intrauterino, presentándose en un 36,6\% y el estudio de García-Cano (2002) [30] en el que concluyeron que la presencia de Actinomyces spp. predominó en las usuarias del dispositivo intrauterino (9,7\%). Igualmente, Torres y Schalper (2002) [31] mostraron que el 86,7\% de mujeres con Actinomyces spp. eran usuarias del dispositivo intrauterino. En la actual investigación, a pesar de que la infección con Actinomyces spp. no presentó asociación estadística con el grupo etario, se registró una prevalencia más alta entre las mujeres mayores de 64 años, llegando a ser el doble que en el grupo de adolescentes (16,7\% frente a 8,1\%), lo que resulta similar a otros estudios previamente realizados [3 I]. Según estos datos, se podría sugerir la posible asociación entre el ambiente de anaerobiosis creado por el uso prolongado del dispositivo intrauterino y el aumento de la relevancia de la infección con Actinomyces spp. en este grupo poblacional.

La prevalencia de Candida spp. en este estudio fue del 5, I\%, lo que concuerda con un estudio previo realizado en Medellín, en el que se reportó que el 5,3\% de usuarias del dispositivo intrauterino presentaban candidiasis vaginal [27]. En otro estudio realizado entre 2010-20। 2 en mujeres de la población general de la ciudad se reportó una menor prevalencia (4,7\%) [23] respecto al actual estudio. De forma similar a lo reportado para Actinomyces spp., la candidiasis se presenta con mayor frecuencia en las adolescentes, lo que podría suponer un mayor grado de exposición a factores de riesgo sexuales, como los descritos previamente [28]. Por su parte, en el presente estudio la prevalencia de Trichomonas vaginalis fue del 1,2\% y no presentó asociación con el grupo etario. Esta prevalencia concuerda con los estudios realizados en la población general de Medellín, con reportes del I,3\% y 0,8\% [23,27], lo que implica que el uso del dispositivo no es relevante para el análisis de la magnitud de esta infección.

Los resultados de esta investigación evidencian que en la población de mujeres usuarias del dispositivo intrauterino la prevalencia y distribución de las infecciones vaginales presenta un comportamiento diferente al encontrado en la población general, siendo de mayor relevancia Actinomyces spp. Esto puede ser sustentado en el hecho que, si bien el cuello del útero cumple una función de barrera física y química que inhibe la entrada de bacterias en el útero, la presencia de un cuerpo extraño como el dispositivo intrauterino, que cuenta con una cola que está expuesta en el exocérvix, crea un ambiente adecuado para la transición de microorganismos hacia el útero. Al mismo tiempo, el dispositivo intrauterino produce cambios bioquímicos, histopatológicos y celulares en el endometrio y la cérvix como la formación de prostaglandinas que derivan en una respuesta inflamatoria que podría aumentar la incidencia de la infección bacteriana [19,32].

En relación con lo anterior, debe indicarse que algunos microorganismos como Candida albicans tienen la capacidad de adherirse a diferentes partes del dispositivo intrauterino, generando biopelículas que parecen estar implicadas en el desarrollo de la vulvovaginitis y su recurrencia [26,33]. Además, el dispositivo intrauterino de cobre también suele asociarse con infecciones vaginales, 
principalmente por su efecto de anaerobiosis debido al material de cobre que liberan radicales libres que reducen las concentraciones de oxígeno en la vagina y generan un ambiente propicio para el crecimiento de Actinomyces spp. y otros microorganismos anaerobios causantes de vaginosis bacteriana [19,32].

Este estudio presenta como limitante que la sensibilidad de la prueba de Papanicolaou para el diagnóstico de infecciones vaginales no es del 100\%, lo que deriva en una leve subestimación de la prevalencia real de estas infecciones. A esto se suma el hecho de que no se evaluó el estado de la microbiota vaginal de las mujeres antes de la inserción del dispositivo intrauterino, no se hizo distinción entre los tipos de dispositivos que usaban las mujeres del estudio y en la fuente de información secundaria no se incluyeron variables relacionadas con el tiempo de uso del dispositivo ni la continuación del uso del DIU en el momento de la toma de la citología, lo que podría explicar la alta prevalencia de Actinomyces spp. encontrada en las adultas mayores. No obstante, el estudio presenta como fortaleza el trabajar con una base poblacional elevada, el registrar la frecuencia de infecciones en mujeres asintomáticas que sin la prueba del Papanicolau no se captarían. Al mismo tiempo se destaca la citología cervicouterina como una prueba sencilla, económica y de amplia cobertura para la población femenina en general.

\section{Conclusiones}

Las infecciones vaginales más prevalentes en usuarias del dispositivo intrauterino son la vaginosis bacteriana y Actinomyces spp.; esta última, al igual que Candida spp., es mayor en este grupo que en las mujeres de la población general, sugiriendo una potencial asociación. Las prevalencias de las diferentes infecciones varían según el grupo etario y el sector de residencia, información relevante para la planeación de programas de prevención y atención en salud sexual y reproductiva.

\section{Bibliografía}

I. Organización Mundial de la Salud, Salud Reproductiva e Investigaciones Conexas. Infecciones de transmisión sexual y otras infecciones del tracto reproductivo: una guía para la práctica básica. Singapur: Organización Mundial de la Salud; 2005.

2. Organización Mundial de la Salud. Infecciones de transmisión sexual. Nota descriptiva No I 10. 2013. Disponible: http://www.who.int/mediacentre/factsheets/fs। I0/es. Consultado: agosto 2015.

3. Organización Mundial de la Salud. Estrategia mundial de prevención y control de las infecciones de transmisión sexual, 2006-2015. 2006. Disponible: http://apps.who.int/gb/ebwha/pdf_files/WHA59RECI/s/Anexo2-sp.pdf. Consultado: agosto 2015.

4. República de Colombia, Ministerio de Salud y Protección Social. Situación de las infecciones de transmisión sexual diferentes al VIH. Colombia 2009 - 2011. 2011. Disponible: https://uww.minsalud. gov.co/salud/Documents/observatorio_vih/documentos/monitoreo_evaluacion/I_vigilancia_salud_publica/a_situacion_epidimiologica/SITUACION\%20DE\%20LAS\%2OINFECCIONES\%20 DE\%20TRANSMISIONI.pdf. Consultado: agosto
2015.

5. Salas N, Ramírez JF, Ruiz B, Torres E, Jaramillo LN, Gómez-Marín JE. Prevalencia de microorganismos asociados a infecciones vaginales en 230 mujeres gestantes y no gestantes sintomáticas del Centro de Salud La Milagrosa en el municipio de Armenia (Colombia). Rev Colomb Obstet Ginecol 2009; 60: 135-142.

6. López-Barbosa N, Castro-Jiménez MÁ, GamboaDelgado EM, Vera-Cala LM. Prevalencia y determinantes de las infecciones vaginales en las mujeres recluidas en una cárcel colombiana. Rev Chil Obstet Ginecol 2009; 74: 77-82.

7. Centros para el Control y Prevención de Enfermedades. Candidiasis. 2015. Disponible: http:// www.cdc.gov/fungal/diseases/candidiasis/index. html. Consultado: agosto 2015.

8. Centros para el Control y Prevención de Enfermedades. Tricomoniasis: Hoja informativa de los CDC. 2015. Disponible: http://www.cdc.gov/std/ spanish/tricomoniasis/stdfact-trichomoniasis-s.htm. Consultado: agosto 2015. 
9. Livengood $\mathrm{CH}$. Bacterial vaginosis: an overview for 2009. Rev Obstet Gynecol 2009; 2: 28-37.

10. Marrazzo JM. Interpreting the epidemiology and natural history of bacterial vaginosis: are we still confused? Anaerobe 2011; 17: 186-190.

II. Centros para el Control y Prevención de Enfermedades. Vaginosis bacteriana: Hoja informativa de los CDC. 2015. Disponible: http://www.cdc.gov/ std/Spanish/vb/STDFact-Bacterial-Vaginosis-s.htm. Consultado: agosto 2015.

12. Flores A, Parrilla I, Urdes E, Quintana V, Gutiérrez V. Guía de práctica clínica de prevención, diagnóstico y tratamiento de la actinomicosis en adultos. 2010. Disponible: http://www.cenetec. salud.gob.mx/descargas/gpc/CatalogoMaestro/480_ GPC_Actinomicosis/GER_ACTINOMICOSIS.pdf. Consultado: agosto 2015.

13. Alemán Mondeja LD, Almanza Martínez C, Fernández Limia O. Diagnóstico y prevalencia de infecciones vaginales. Rev Cubana Obstet Ginecol 2010; 36: 62-103.

14. Hubacher D. Intrauterine devices \& infection: review of the literature. Indian J Med Res 20।4; 140 Suppl: S53-57.

15. Pigrau C, Dolores Rodríguez-Pardo M. Infecciones asociadas a dispositivos para drenaje de las vías urinarias. Infecciones del tracto genital relacionadas con los dispositivos protésicos. Enferm Infecc Microbiol Clin 2008; 26: 299-310.

16. República de Colombia, Ministerio de la Protección Social, Bienestar Familiar, Profamilia, Agencia de los Estados Unidos para el Desarrollo Internacional (USAID). Encuesta Nacional de Demografía y Salud 20 I 0. 20 I I. Disponible: http://dhsprogram. com/pubs/pdf/FR246/FR246.pdf. Consultado: agosto 2015 .

17. República de Colombia, Instituto Nacional de Salud. Guía control de calidad para la toma, procesamiento e interpretación en muestras de citología de cuello uterino. 2009. Disponible: http://www.ins. gov.co/tramites-y-servicios/programas-de-calidad/ Control\%20de\%20Calidad\%20en\%20Citologa\%20 de\%20Cuello\%20Uterino/GUIA\%20DE\%20CONTROL\%20DE\%20CALIDAD\%202009.pdf. Consultado: agosto 2015.

18. Karani A, De Vuyst H, Luchters S, Othigo J, Mandaliya K, Chersich MF, et al. The Pap smear for detection of bacterial vaginosis. Int J Gynaecol Obstet 2007; 98: 20-23.

19. Calvo Pérez A, Lozano Sánchez M, Agüera Ortiz J, Tubau Navarra A, Romero Gámez M. Actinomicosis abdomino-pélvica y DIU. Toko-Gin Pract 2002; 61: 364-368.

20. Castro MI, Abratte O, Barocchi M, Musacchio ML. Coloración de Papanicolaou y su importancia en el diagnóstico de las infecciones cervicovaginales. Acta Bioquím Clín Latinoam 2004; 38: 199-202.

21. Barcelos MRB, Vargas PRMd, Baroni C, Miranda
AE. Infecções genitais em mulheres atendidas em Unidade Básica de Saúde: prevalência e fatores de risco. Rev Bras Ginecol Obstet 2008; 30: 349-354.

22. Villaseca R, Ovalle A, Amaya F, Labra B, Escalona $\mathrm{N}$, Lizana $\mathrm{P}$, et al. Vaginal infections in a Family Health Clinic in the Metropolitan Region, Chile]. Rev Chilena Infectol 2015; 32: 30-36.

23. Cardona-Arias JA, Herrera-Posada D, ValenciaArredondo M. Prevalencia de resultado positivo de la citología para vaginosis bacteriana, candidiasis y tricomoniasis en una Empresa Social del Estado de Medellín (Colombia), 20I0-20I2. Rev Colomb Obstet Ginecol 20 I4; 65: 206-2I4.

24. González-Pedraza Avilés A, Mota Vázquez R, Ortiz Zaragoza C, Ponce Rosas RE. [Factors of risk of bacterial vaginosis]. Aten Primaria 2004; 34: 360365.

25. Venegas G, Boggiano G, Castro E. Prevalencia de vaginosis bacteriana en trabajadoras sexuales chilenas. Rev Panam Salud Publica 20 I I; 30: 46-50.

26. Martínez Benavides M, Navalón Bonal Z, Labrador Baena R. Protocolos SEGO/SEC. Anticoncepción intrauterina. Sociedad Española de Contracepción. 2013. Disponible: http://sec.es/descargas/ PS_Anticoncepcion_intrauterina.pdf. Consultado: agosto 2015.

27. Tamayo Acevedo LS, Guevara Romero E, López Martínez MI. Vaginosis bacteriana, Candidiasis y Tricomoniasis por citología cervico-vaginal en mujeres del régimen subsidiado, Medellín - Colombia, 2008. Rev Salud Pública de Medellín 20 I0; 4: 87- 100.

28. Organización Mundial de la Salud. Adolescentes: riesgos para la salud y soluciones. Nota descriptiva N³45. 2014. Disponible: http://www.who.int/mediacentre/factsheets/fs345/es/. Consultado: agosto 2015.

29. Arenas Osorio AE, Osorio Arcila $\mathrm{Y}$, Cardona Arias JA. Prevalencia de actinomicosis vaginal y su asociación con el uso del dispositivo intrauterino en tres instituciones de salud de Antioquia, 20 I3. CES Medicina 2015; 29: 47-57.

30. García-Cano Ramos E, Camargo-Velasco A, Carrera-Terrazas A, Galán-Gutiérrez NA, Núñez Rasilla V, Rojas Castañeda ML. Detección de Actinomyces spp de muestras cérvico-vaginales de mujeres con y sin dispositivo intrauterino. Bioquimia 2002; 27: 60-68.

31. Torres S, Schalper K. Análisis de la presencia de actinomicosis pelvica en mujeres de una comunidad rural en Chile. Rev Chil Obstet Ginecol 2002; 67: 232-236.

32. Baris, II, Keles AN. [A review on the impact of IUD in cervical cytology: Mardin Region Data]. Turk Patoloji Derg 2013; 29: 51-57.

33. Kaliterna V, Kucisec-Tepes N, Pejkovic L, Zavorovic $S$, Petrovic $S$, Barisic $Z$. An intrauterine device as a possible cause of change in the microbial flora of the female genital system. J Obstet Gynaecol Res 2011; 37: 1035-1040. 


\section{$\pi$ Laboratorio or Clínico \\ Y Hematológico}

Creemos en los sueños de todos los colombianos que llevan en la sängre confianza

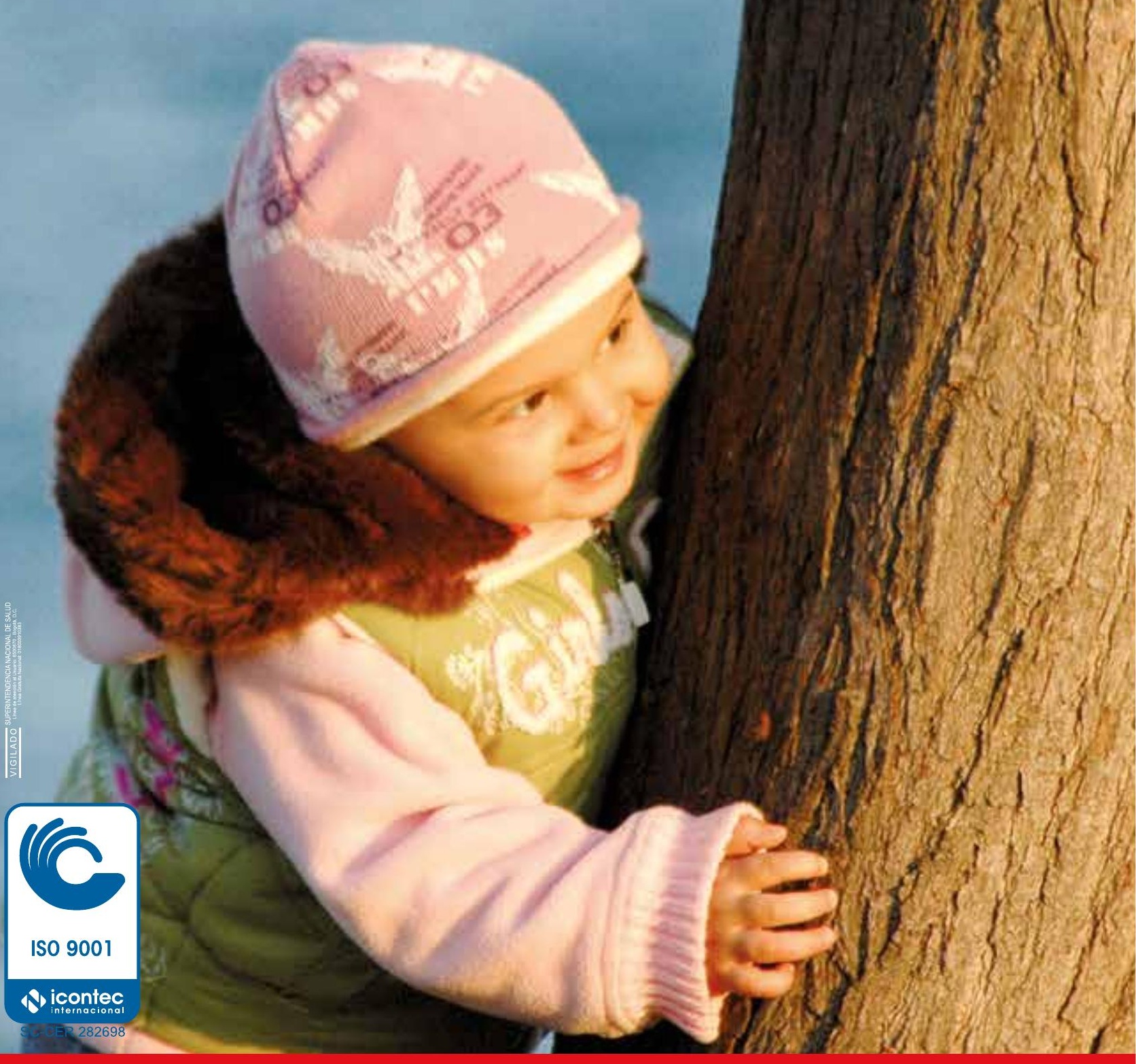

Sede Principal Poblado: Carrera 43C No. 5-33

Toma de Muestras: Centro Comercial Sandiego, Torre Norte, Piso 10, No. 1034 